Лукин В.А. 100 задач по семиотике текста: Учебное пособие. М.: Флинта, 2019. 144 с.

I.V. Ruzhitskiy (Moscow, Russia)

\title{
Lukin V.A. 100 Tasks on Semiotics of a Text: Tutorial. Moscow. Flinta Publ. 2019. 144 p.
}

Рецензируемое пособие В.А. Лукина - книга не совсем обычная. Это, конечно, в первую очередь учебное пособие, но одновременно - сборник занимательных и в своем большинстве совершенно нетривиальных задач по семиотике текста, основанных на четко сформулированных теоретических положениях.

Если говорить об адресате учебника, то книга, по словам ее автора Владимира Алексеевича Лукина, является пособием к вузовским курсам «Семиотика», «Теория текста», «Теория коммуникации», а также спецкурсам «Семиотика денег» и «Социальный кризис в лингвосемиотическом освещении», читаемым на филологическом факультете. Во многом оригинальный характер этих курсов не мог не отразиться и на содержании пособия, что очевидным образом прослеживается как в его структуре, последовательном представлении задач по семиотике текста, так и в содержании самих задач, обусловленном авторской концепцией, краткое изложение которой дается в пособии.

Задачки, задания и головоломки парадоксального типа всегда использовались в высшей и средней школе в преподавании самых разных предметов, как естественных, так и гуманитарных, - физики, химии, математики, философии, лингвистики и т. д. В последнее время, однако, мы не можем не наблюдать всё большей стандартизированности в обучении, которая, несомненно, должна иметь место в учебном процессе, но - именно место: достижение стандарта, следование какому-то образцу, его заучивание не может являться основной целью обучения, что мы довольно часто видим в предлагаемых вузовских и школьных программах, а также различного вида контрольных материалах.

Справедливости ради следует отметить, что сборники задач по разным предметам есть и сейчас, но, к сожалению, они используются лишь как своего рода дополнительный материал, а не в качестве системных учебных пособий. Создается впечатление, что педагогический опыт, накапливаемый столетиями, по использованию в преподавании гуманитарных наук основанных на парадоксе логических задач, полностью утерян или забыт, как и сама логика. 
В Советском Союзе логику с 1949 по 1956 г. преподавали в школах как обязательный предмет. Пользовались учебником «Логика», созданным специально для средней школы С.Н. Виноградовым и А.Ф. Кузьминым. Учебник очень даже серьезный, включающий в себя - правда, в небольшом количестве - и логические задачи. Потом логику как предмет обучения «закрыли», как в рамках борьбы с культом личности Сталина «закрывали» многое, посчитав слишком сложным. Вопрос о сложности учебных материалов по разным предметам, предлагаемых для чтения и изучения литературных произведений и т. д. - тема отдельная, которая всегда была и остается актуальной. Когда-то Ф.М. Достоевский настаивал на том, чтобы исключить из школьной хрестоматии «Слово о полку Игореве» как слишком сложное с точки зрения языка произведение, сейчас же многие педагоги и методисты, приводя уже свои аргументы, пытаются доказать нецелесообразность включения «Преступления и наказания» в школьную программу. Действительно, идея романа Достоевского сложна и непонятна для многих или даже для большинства, но, если следовать такому подходу, в качестве учебного материала следует оставить только лозунги или всё то, что никакого понимания не требует, требует только заучивания наизусть. Важен сам процесс понимания, развития этой способности, но не его результат, предлагаемый в виде готовой схемы. А развивать такую способность можно, в общем-то, на самом разном материале: литературном произведении или статье конституции, философском трактате или рекламном тексте и т. д. Понимание как раз и основано на логике, на логике и диалоге.

В 1990-х логику сделали факультативным предметом, но мы отлично знаем, чем становится всё факультативное в наших школах. Примерно такая же ситуация была и в вузах, хотя здесь «Логика» в качестве обязательного предмета просуществовала намного дольше. Наиболее успешное преподавание логики - как раз через решение логических задач, чаще всего парадоксального характера. И проблема не в их сложности, часто иллюзорной, а в способности преподавателя увлечь своих учеников, и увлечь как раз парадоксом. Чтобы формальная логика не стала формальной, надо обладать способностью преподавать неформально. Это же можно сказать о преподавании любого предмета. Умение думать, размышлять действительно осложняет жизнь человека, тем не менее человек думающий все-таки в конечном счете полезнее для общества, чем человек, не умеющий этого делать. Дело даже и не в обществе, а в самодостаточности и вообще в человеческой сущности. «Думать вредно» - оно, конечно, удобнее. Да и зачем в нашей жизни парадокс? Современная жизнь требует однозначности... Однако если перед нами стоит цель познания окружающего мира, а также методическая и воспитательная задача обучения способам такого познания, то без логики и семиотики, науки, исследующей свойства знаков и знаковых систем, обойтись невозможно. «Тайна мира символами не закрывается, а именно раскрывается, в своей подлинной сущности, то есть как тайна» (П.А. Флоренский).

Преподавание семиотики сродни преподаванию логики, и кажущаяся сложность рецензируемой книги именно кажущаяся, если, конечно, вникнуть в авторский метаязык и - в авторскую логику. Как абсолютно справедливо указывает В.А. Лукин в предисловии к своей книге, необходимо «изложить узловые понятия и идеи семиотики текста в проблемном ключе, стараясь, где уместно, сделать это как можно проще» (стр. 3), а «лучшей формой для реализации такого намерения является учебная задача» (там же). Задача, таким образом, становится не столько учебным материалом, сколько методом обучения. И, наконец, «желая, чтобы “100 задач” решались не как и не чем угодно (и не кем угодно), автор вынуж- 
ден был включить в пособие “Идеи, понятия и термины, необходимые для решения задач"», раздел, в котором «собраны фрагменты статей автора за последние, примерно, 10 лет <..> проанализированы основные понятия семиотики текста, предложены формулировки ряда ее узловых проблем и даны возможные решения проблем» (стр. 8).

Скажем несколько слов о структуре рецензируемого пособия. Книга состоит из предисловия, двух разделов и списка литературы - в основном работ по семиотике текста и семантике.

Первый раздел - Задачи и головоломки» - структурирован следующим образом: «Знаки и сообщения», «Коды, сообщения и произведения» и «Коммуникативно-семиотические ситуации». В нем также даются источники использованного материала. Приведем примеры предлагаемых задач и головоломок.

7. Какое из трех однотипных изображений в семиотическом смысле противопоставлено двум другим? (стр. 14)

9. (стр. 15)
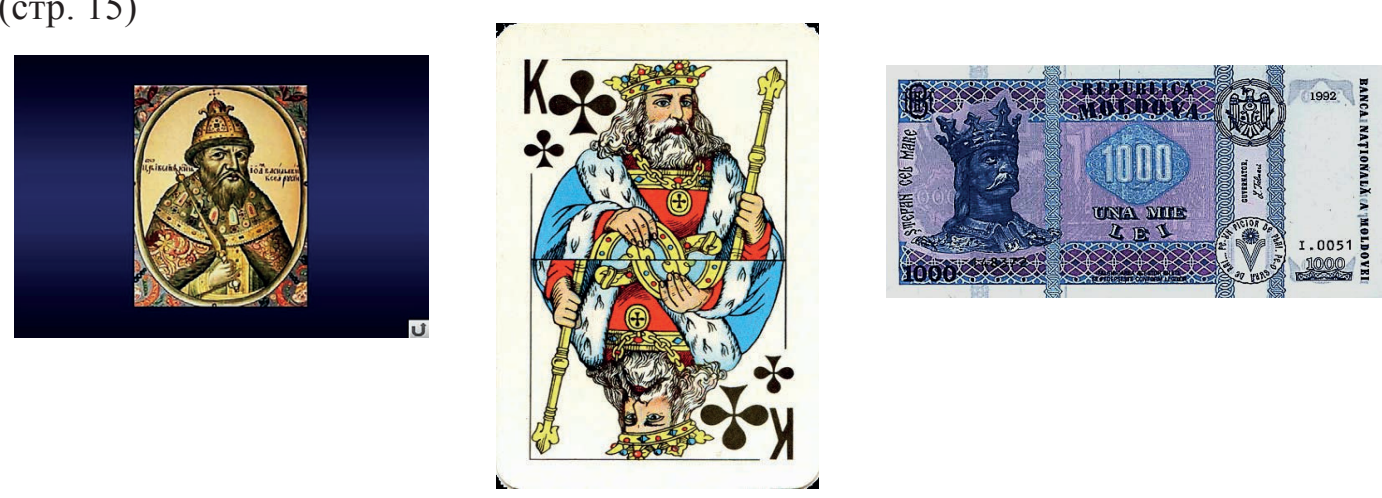

ЗАПАДНОАФРИКАНСКАЯ ПИСЬМЕННОСТЬНСИБИДИ

«Происхождение нсибиди неясно. Согласно традиции, эта письменность возникла среди народа угакима (иначе эбе, или уянга) - ответвления племени ибо, живущего между Икорана (на реке Кросс-Ривер) и Увет (на реке Калабар). Существует прелестная сказка о том, как уянга научились письму от обезьян бабуинов, называемых идиоками, которые собирались вокруг их костров».

«Следует отметить, что местное население стремится скрыть от европейцев свое знакомство с письменностью. К тому же нсибиди употребляется главным образом для выражения любви, а под это понятие подводится целый ряд слов, в умении писать которые любой уважающий себя местный житель предпочёл бы не признаваться» (Дирингер Д. Алфавит. М., 1963. С. 184-185).

В этой письменности имеются, в частности, следующие сообщения:

$$
\begin{aligned}
& \text { - 'супружеская любовь' } \\
& \text { I } \\
& \text { с с ним' }
\end{aligned}
$$

- К какому типу знаков (по Ч.С. Пирсу) следовало бы отнести приведенные выше? 
Два новых сообщения:

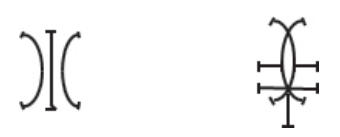

- В чем причина того, что легко установить значение первого из сообщений и практически невозможно значение второго?

16. (стр. 19).

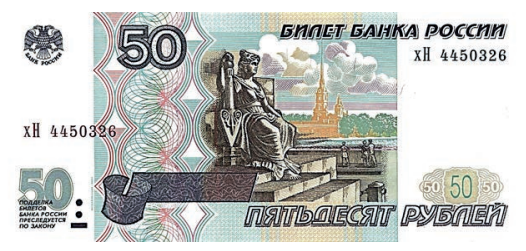

- Увеличенный фрагмент пятидесятирублевой купюры свидетельствует об одной странности в изображении скульптуры - символа Невы, - причем сама скульптура этой странности лишена. Какова эта странная особенность и при каких условиях она может или не может расиениваться как знак?

Решений к задачам, т. е. ключей, в пособии нет, что нам представляется вполне логичным и правильным, если учитывать имплицитно присутствующую в книге идею - в первую очередь помочь студентам (на самом деле, не только учащимся вуза) научиться рассуждать, готовое решение же будет ограничивать развитие этой способности. В конце концов, в данном случае важнее не сам ответ на поставленный вопрос, а тот путь, посредством которого к этому ответу можно подойти. Ключом, если уж говорить об обязательности выполнения этого методического требования, может служить теоретическая часть пособия. Неподготовленному же читателю в начале каждого из трех разделов «Задач и головоломок» предлагаются образцы решений - этого вполне достаточно.

Во втором разделе книги - «Понятия, идеи и термины, необходимые для решения задач» - в предельно компактной форме представлены результаты многолетних размышлений автора, касающиеся проблем семиотики текста. Это и определение самого понятия «текст», и соотношение текста и «не-текста», и функциональная обусловленность текста, и некоторые другие. Полагаем, что теоретический и методический аппарат данного раздела пособия является вполне достаточным для решения задач и головоломок, которые даются в первом разделе.

Как и любое значимое произведение, а учебник Владимира Алексеевича Лукина вне всякого сомнения следует считать таковым, пособие «100 задач по семиотике текста» не может не вызвать определенных вопросов, предложений, возможно, даже возражений. Так, вполне очевидным для нас является то, что автор создавал свой учебник в первую очередь для себя, в соответствии со своей теорией и для своей теории, для своих учебных курсов и для своих студентов, наконец, для своего стиля общения со студентами и «стиля» обращения к материалу. Так, в общем-то, и должно быть. Тем не менее при этом естественным образом возникает вопрос о том, насколько широко может использоваться данный материал другими его пользователями? И для каких еще, кроме предлагаемых автором, курсов? Хотелось бы высказать и такое соображение: решение любого рода задач, не только по семиотике, влечет за собой некоторый автоматизм при их выполнении, что, по большому счету, нарушает исходную идею рецензируемой книги - развитие спо- 
собности к пониманию через парадоксальное осмысление действительности. Из этого противоречия есть несколько выходов; например, можно на каком-то этапе поставить перед учащимися задачу самим придумать какую-нибудь головоломку или логический парадокс, которую легко упростить (или, наоборот, усложнить), предложив какие-либо исходные данные. Обозначенный в пособии терминологический словарь, на наш взгляд, не помешало бы расширить, отдельно включить хрестоматийную часть - отрывки из известных работ, посвященных семиотике текста. Возможно, в последующих изданиях книги ее автор как-то отразит данные соображения. Однако и без этого учебное пособие «100 задач по семиотике текста», безусловно, будет востребовано преподавательской и студенческой аудиторией и, смеем полагать, что, несмотря на весьма непростой материал, представленный в нем, окажется интересным для широкого круга читателей.

Сведения об авторе:

Игорь Васильевич Ружицкий, доктор филол. наук

доцент

филологический факультет

МГУ имени М.В. Ломоносова
Igor V. Ruzhitskiy,

Doctor of Philology

Associate Professor

Philological Faculty

Lomonosov Moscow State University

konnitie@mail.ru 